\title{
Development of a Biosensor for the Detection of Acetoin during Wine Fermentation ${ }^{+}$
}

\author{
Denise Molinnus 1, Lukas Muschallik ${ }^{1}$, Johannes Bongaerts ${ }^{1}$, Thorsten Selmer ${ }^{1}$, \\ Torsten Wagner ${ }^{1}$, Petra Siegert ${ }^{1}$, Michael Keusgen ${ }^{2}$ and Michael J. Schöning 1,* \\ 1 Institute of Nano and Biotechnologies (INB), FH Aachen, Campus Jülich, 52428 Jülich, Germany; \\ molinnus@fh-aachen.de (D.M.) muschallik@fh-aachen.de (L.M.); bongaerts@fh-aachen.de (J.B.); \\ selmer@fh-aachen.de (T.S.); torsten.wagner@fh-aachen.de (T.W.); siegert@fh-aachen.de (P.S.) \\ 2 Institute of Pharmaceutical Chemistry, Philipps-University Marburg, 35032 Marburg, Germany; \\ keusgen@staff.uni-marburg.de \\ * Correspondence: schoening@fh-aachen.de \\ + Presented at the 5th International Symposium on Sensor Science (I3S 2017), Barcelona, Spain, \\ 27-29 September 2017.
}

Published: 14 December 2017

Acetoin is most commonly used in food, flavor, cosmetics and chemical synthesis and is formed during fermentation by the microbial activity of lactic bacteria and yeast. For example, acetoin is the key compound of the biosynthesis of diacetyl which is an important wine flavorant synthesized during alcoholic and malolactic fermentation. Therefore, the detection of acetoin content during the fermentation process could improve the quality of wine due to its involvement in its bouquet. A silicon-based biosensor chip for the detection of acetoin has been developed with a novel acetoin reductase from B. clausii. Acetoin will be reduced by the enzyme while NADH will be oxidized to $\mathrm{NAD}^{+}$. This reaction is accompanied by a $\mathrm{pH}$ shift that can be detected by a capacitive field-effect sensor. The sensor's ability has been investigated using constant-capacitance measurements at acetoin concentrations from $50 \mu \mathrm{M}$ to $200 \mu \mathrm{M}$ in MES (2-(N-morpholino)ethanesulfonic acid) buffer at $\mathrm{pH}$ 6.8. The possibility to monitor acetoin by this new type of biosensor could provide an advantage in controlling the fermentation in winemaking.

Acknowledgments: The authors thank the Ministerium für Innovation, Wissenschaft und Forschung des Landes Nordrhein-Westfalen for financial support (Förderprogramm FH-Struktur 2016).

(C) 2017 by the authors. Licensee MDPI, Basel, Switzerland. This article is an open access article distributed under the terms and conditions of the Creative Commons Attribution (CC BY) license (http://creativecommons.org/licenses/by/4.0/). 